\title{
CVD SYNTHESIS OF GRAPHENE FROM ACETYLENE CATALYZED BY A REDUCED CUO THIN FILM DEPOSITED ON $\mathrm{SiO}_{2}$ SUBSTRATES
}

\author{
ANDREA CORTÉS $S^{a,{ }^{*},}$ CARLOS CELEDÓN ${ }^{a, b}$ AND RAMÓN ZARATEc \\ ${ }^{a}$ Universidad Técnica Federico Santa María, Departamento de Física, Avenida España 1680, Valparaíso-Chile, \\ ${ }^{b}$ Instituto Balseiro (U. N. de Cuyo and CNEA), Avenida Bustillo 9500, Bariloche-Argentina, \\ ${ }^{c}$ Universidad Católica del Norte, Departamento de Fisica, Facultad de Ciencias, Casilla 1280, Antofagasta-Chile
}

\begin{abstract}
Few-layer graphene was grown by Chemical Vapor Deposition on a CuO thin film pre-deposited by sputtering on $\mathrm{SiO} / \mathrm{Si}$ substrates using acetylene as the carbon source. After evaporation of metal, graphene lies directly in contact with the $\mathrm{SiO} 2$ dielectric layer. Raman spectroscopy was used to confirm the presence of a single and/or few-layers of graphene. This procedure does not requiring any post processing to transfer the thin film onto a dielectric substrate or the use of ultra-high vacuum during synthesis.
\end{abstract}

Keywords: Graphene, Cupric Oxide, CVD

\section{INTRODUCTION}

The carbon can adopt various structures such as diamond, graphite (3D), graphene (2D), nanotubes (1D) to fullerenes (0D). With exception diamond whose structure is amorphous, others carbon allotropes are based on the same arrangement: Graphene. This is a single sheet formed by a hexagonal arrangement of $\mathrm{sp}^{2}$ hybridized carbon atoms, with one atom thick and this structure can describe other allotropes of carbon. Thus we have that: the graphite consists of stacks of graphene sheets, nanotubes are formed by a sheet rolled around it-self and finally fullerenes are formed by a graphene sheet containing pentagons and hexagons. The graphene first was isolated and observed by Novoselov et. al. in $2004^{1}$, using the mechanical exfoliation of highly ordered pyrolytic graphite (HOPG), this method has been widely used to study by Raman analysis to characterize the number of layers but is limited to small areas. This occurrence originates an avalanche of experimental and theoretical studies related to electrical and optical properties of graphene as well the developing new synthetic methodologies for their production.

Other methods studied are: (1) chemical exfoliation from bulk graphite through the intercalation and oxidation-reduction of graphite, the graphene is obtained in aqueous suspension, but the material has many defects ${ }^{2,3}$; (2) graphene growth by thermal decomposition of $\mathrm{SiC}^{3}$ under conditions of high temperature and vacuum through sublimation of the silicon atoms, disadvantage is the cost of $\mathrm{SiC}$ and (3) Chemical vapor deposition (CVD) ${ }^{3}$ that consists in the decomposition of a gaseous hydrocarbon (methane, ethylene, acetylene, etc.) over a metallic substrate (catalyst) at high temperature, graphene grows on the metal surface. Latter is a simple process with lower cost, and it has been developed methodologies for transfer of graphene to other substrates.

Chemical vapor deposition (CVD) synthesis is a technique widely used to grow graphene on metallic substrates such as Copper $(\mathrm{Cu})$ and Nickel $(\mathrm{Ni})$. Copper, unlike nickel, allows better control of the growth of graphene due to the low bulk carbon solubility. Copper has been extensively researched in the last decade as a substrate for graphene (mono- and poly-crystalline), in the form of foil or thin film grown in High Vacuum (HV) or Ultra High Vacuum (UHV) conditions ${ }^{4-6}$. Direct deposition of graphene on dielectric surfaces is of great interest given their potential use in sensor fabrication and electronic or optical applications ${ }^{7-11}$

In this study direct growth of graphene or few-layer graphene (FLG), without any transfer process onto a silicon dioxide $\left(\mathrm{SiO}_{2}\right)$ substrate by CVD was used. An intermediate thin film of cupric oxide ( $\mathrm{CuO})$, pre-deposited by DC sputtering was applied as catalysts. Unlike e-beam evaporation or resistive evaporation, DC sputtering is fast and easy to implement at industrial level. Figure 1 represents a schematic picture of the surface after growth is completed, revealing the possibility of finding a complex structure at the surface interface.

\section{EXPERIMENTAL}

The $\mathrm{SiO} 2 / \mathrm{Si}$ substrate was prepared through dry thermal oxidation in a horizontal furnace (Lindberg) with a quartz tube at $1100^{\circ} \mathrm{C}$. An Oxygen flow 100 standard cubic centimeter cubic per minute $(\mathrm{sccm})$ at ambient pressure was applied on a $\mathrm{Si}(100)$ wafer during 340 minutes to produce a $\mathrm{SiO} 2$ layer with $300 \mathrm{~nm}$ thick ${ }^{12}$, which was estimated by the time of synthesis and blueviolet color $^{13}$ of samples. The $\mathrm{CuO}$ films were deposited over the substrate at room temperature by DC sputtering, using a standard 2 SPI Module ${ }^{\mathrm{TM}}$ Sputter/ Carbon Coaters with a Quartz Crystal Thickness Monitor system was used. This system allows estimate the thickness of $\mathrm{CuO}$ deposited, for the conditions used, the films were of $\sim 450 \mathrm{~nm}$ thick.

Graphene growth was performed in 3 stages (Figure 2) under vacuum obtained by a mechanical pump. First copper oxide is reduced in presence of hydrogen. Then the acetylene $\left(\mathrm{C}_{2} \mathrm{H}_{2}\right)$, which is gaseous carbon source, is incorporated what resulted in the graphene growth. Finally, copper is evaporated from underneath, leaving graphene in contact with the $\mathrm{SiO} 2$ substrate ${ }^{11}$.

First stage: The temperature was risen up to $1000^{\circ} \mathrm{C}$ in a $\mathrm{H}_{2}$ ambient at a rate of $90^{\circ} \mathrm{C} / \mathrm{min}$, with the purpose of reducing the pre-deposited $\mathrm{CuO}$ thin film?.

Second Stage: The sample was kept at $1000^{\circ} \mathrm{C}$ and exposed to a gas mixture, with a 7:1 volume ratio of $\mathrm{H}_{2} / \mathrm{C}_{2} \mathrm{H}_{2}$. The acetylene flow was applied during 6 minutes to grow graphene islands on the surface.

Third Stage: After graphene growth was achieved, the sample was kept at $1000^{\circ} \mathrm{C}$ in a $\mathrm{H}_{2}(35 \mathrm{sccm})$ ambient during $50 \mathrm{~min}$, the $\mathrm{H}_{2}$ flow was subsequently reduced to $6 \mathrm{sccm}$ for 3 hours, to promote in the evaporation of the copper film, leaving back an intact the graphene layer ${ }^{10}$. The sample was later cooled down in a $\mathrm{H}_{2}$ environment $(6 \mathrm{sccm})$ until $700{ }^{\circ} \mathrm{C}\left(3^{\circ} \mathrm{C} / \mathrm{min}\right)$. From this point on, the sample reached room temperature without temperature control but keeping the $\mathrm{H}_{2}$ flow constant.

Raman spectroscopy was carried out at room temperature with a Witec Confocal Raman Microscope alpha300R. The laser excitation $(\lambda=633 \mathrm{~nm})$ power was estimated by examining the HOPG G band. It is been shown that sample heating can induced important wavenumber shifts in graphene ${ }^{14}$. By keeping a low excitation power only the sample's intrinsic properties appear in the Raman spectra, without the influence of temperature dependence.

\section{RESULTS AND DISCUSSION}

While raising the temperature to $1000^{\circ} \mathrm{C}$, the thin $\mathrm{CuO}$ film is reduced, in a $\mathrm{H}_{2}$ environment. Due to subsequent oxygen diffusion a new oxide layer is formed ${ }^{15}$ until the process is completed. This mechanism reduces the catalytic activity of the $\mathrm{Cu}$ substrate, favoring the formation of a single layer graphene.

The reduction of $\mathrm{CuO}$, occurs simultaneously with the graphene growth. At the end of the process graphene lays directly over the dielectric surface $\left(\mathrm{SiO}_{2}\right)$, after a prolonged evaporation, as shown in Figure 1. 


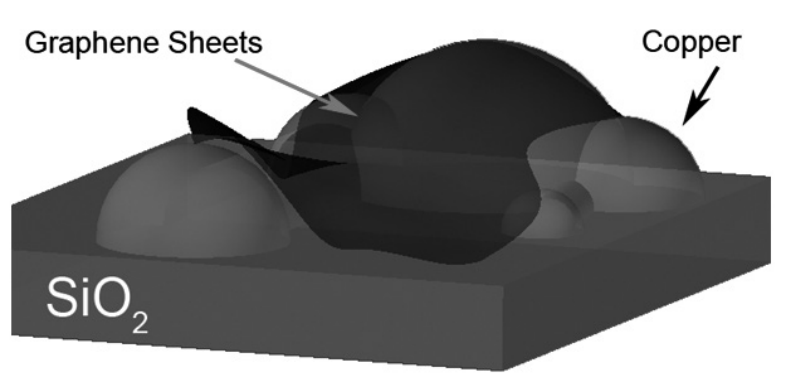

Figure 1. The schematic image of a graphene sheet grown on $\mathrm{SiO}_{2}$ partially covered by $\mathrm{Cu}$. Magenta, brown and the black transparent surface represent respectively $\mathrm{SiO}_{2}$, the $\mathrm{Cu}$ agglomerates and the graphene sheets.

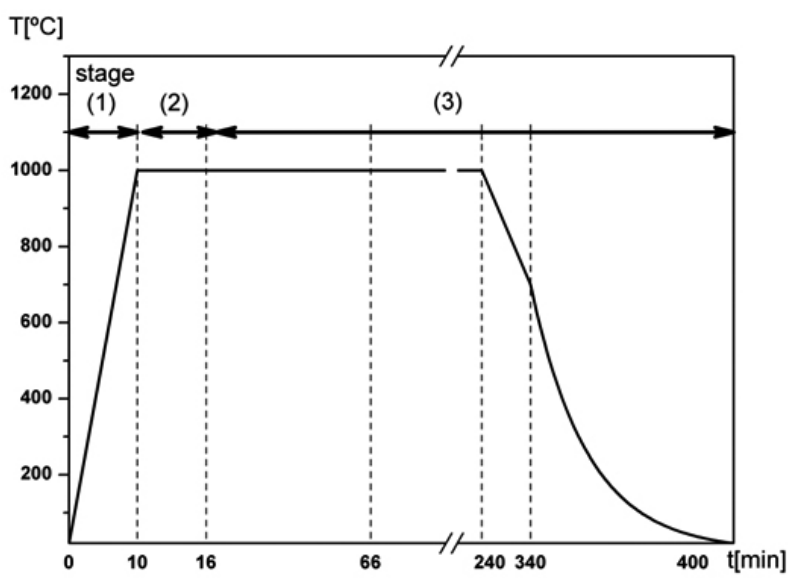

Figure 2. Time dependence of the experimental treatment. The $\mathrm{H}_{2}$ flow rates are different for each one of the different regimes: Stage (1) oxygen reduction, $\mathrm{H}_{2} / 35 \mathrm{sccm}$; stage (2) graphene growth, $\mathrm{C}_{2} \mathrm{H}_{2} / 5 \mathrm{sccm}$ and $\mathrm{H}_{2} / 35$ sccm for five minutes. Stages (3) copper evaporation, from 16 up to 60 minutes the furnace is kept under a flow of $\mathrm{H}_{2} / 35 \mathrm{sccm}$, which is later reduced to $\mathrm{H}_{2} / 6 \mathrm{sccm}$. Stage (4) slow and free cool down. Both final stages occur without $\mathrm{C}_{2} \mathrm{H}_{2}$ flow under $6 \mathrm{sccm}$ of $\mathrm{H}_{2}$.

The samples were characterized by Raman spectroscopy, a method, which is widely used for characterizing graphene properties and carbonaceous materials $s^{16,17}$. Raman spectroscopy was carried out directly on the synthesis products, without any post chemical or thermal treatment in order to obtain further purification or atomic rearrangement.

Figure 3 shows the optical image of a $\mathrm{CuO}$ sample $(450 \mathrm{~nm}$ thick) reduced on silicon oxide after 6 min of CVD growth. Evaporated areas and de-wetting of the metal occurs simultaneously. Agglomeration of metal structures can be detected optically. Raman spectra were used to characterize the presence of graphene (laser excitation $\lambda=633 \mathrm{~nm}$ ). The Raman excitation power was estimated by measuring the HOPG G band $\left(1582 \mathrm{~cm}^{-1}\right)^{18}$. As shown in Figure 4a) we determine the presence of single layer graphene by measuring the $I_{G} / I_{2 D}$ intensity ratio. The $\mathrm{D}$ peak is comparable to the $\mathrm{G}$ intensity.

In Figure 4b) we can observe two main differences with respect to the previous image (4a): a smaller $\mathrm{I}_{\mathrm{G}} / \mathrm{I}_{2 \mathrm{D}}$ intensity ratio, but still consistent with the presence of graphene and the second one, a larger $\mathrm{I}_{\mathrm{D}} / \mathrm{I}_{\mathrm{G}}$ intensity ratio. In addition, the spectrum shows a stronger $\mathrm{D}^{\prime}$ intensity what is consistent with the presence of defects in the graphene layer ${ }^{19}$.

The presence of the $\mathrm{D}$ band (mean value of $1336 \mathrm{~cm}^{-1}$ ) in all Raman spectra is agrees with presence of wrinkles and structural defects in the graphene layer ${ }^{16}$, and edge defects at domain boundaries ${ }^{20}$.

Hydrogen was used during copper evaporation and also after graphene growth. While $\mathrm{Cu}$ is evaporated, hydrogen becomes more effective in etching the graphene flakes over the metallic surface. This effect does not occur if graphene is directly in contact with $\mathrm{SiO}_{2}^{6}$. This phenomenon explains the defects level of graphene, evident by the D and D' Raman bands (see figure 4(b) and figure 5(b)). Using Ar or $\mathrm{H}_{2}$ diluted in Ar, this damage can be reduced.

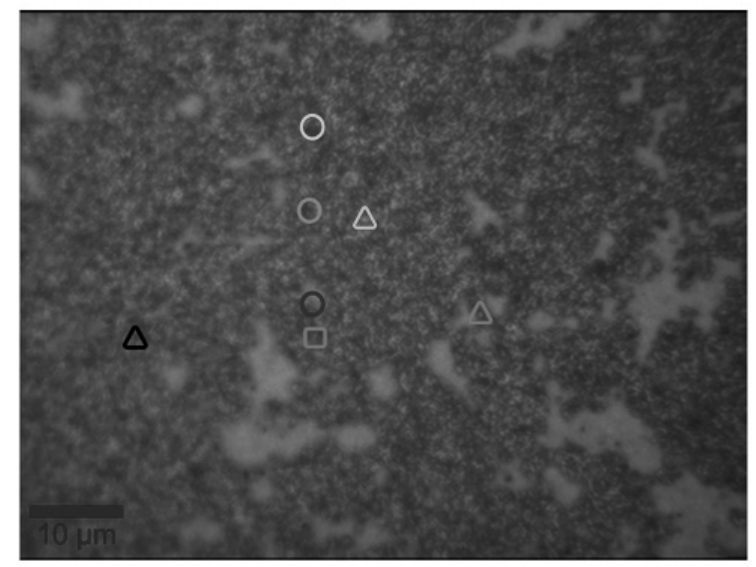

Figure 3. Optical microscopy image of a sample after graphene growth on $\mathrm{CuO}$. The thin $\mathrm{CuO}$ (450 nm thick) film is partially reduced to $\mathrm{Cu}$ in $\mathrm{a}_{2}$ ambient. The colors circle and triangles show the positions on the sample over the Raman spectra were collected.

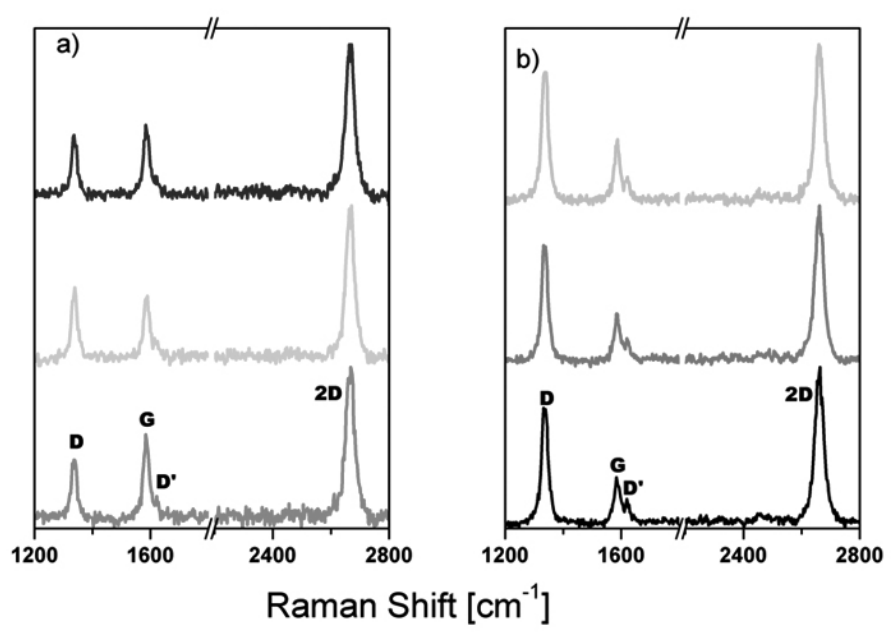

Figure 4. a) Graphene Raman shift on $\mathrm{SiO}_{2}$, recorded on different sections of the surface (highlighted as circles on Figure 3, with the corresponding color coding). The first spectrum is consistent with a bilayer graphene. The last two spectra corresponded to single layer graphene. b) Graphene grown on the same substrate, but covering to the $\mathrm{Cu}$ nanocluster. In both cases, a) and $\mathrm{b}$ ), the $\mathrm{I}_{\mathrm{G}}{ }^{\prime}$ $\mathrm{I}_{2 \mathrm{D}}$ ratio is consistent with graphene. All spectra were background subtracted.

The Raman map displayed in figure 5 shows the $\mathrm{I}_{\mathrm{G}} / \mathrm{I}_{2 \mathrm{D}}$ ratio measured on the red square shown in figure 3 . The map was obtained by subtracting the background of the individual Raman spectrum for each bit. These Raman spectra are similar to those previously reported for graphene grown on Copper ${ }^{6,21,22}$. The $\mathrm{G}$ band was found to be at $1587 \mathrm{~cm}^{-1}$ with a full width at half maximum (FWHM) of $23 \mathrm{~cm}^{-1}$.

There are two characteristic zones which are differentiated by the value of the $2 \mathrm{D}$ band. In Figure 3, the surface regions labeled with a circles have a $2 \mathrm{D}$ band is at $2666 \mathrm{~cm}^{-1}$. This value is expected due to the substrate-graphene interaction ${ }^{5,23}$ (including residual Cu metal), with a FWHM(2D) $33 \mathrm{~cm}^{-1}$, while 2D band is $2660 \mathrm{~cm}^{-1}$, keeping the same FWHM(2D) in regions labeled with triangles. This difference in the 2D peaks (circles and triangles in figure 3 ) is directly linked to different collection sites. This point could be located over $\mathrm{Cu}$ clusters, directly on $\mathrm{SiO}_{2}$ or even as a suspended flake ${ }^{23}$. An improved graphene contact with the $\mathrm{SiO}_{2}$ substrate has been shown to correlate well with the larger $\mathrm{I}_{2 \mathrm{~d}} / \mathrm{I}_{\mathrm{G}}$ Raman ratios ${ }^{24}$.

The $\mathrm{D}$ bands intensity is mainly related to edge effects and could be linked to the small size of the graphene flakes. This is clearly an interesting parameter to look into, while considering new mechanisms to improve the synthesis process. The presence of structural defects has been related to an enhanced width of the $\mathrm{G}$ band (FWHM of $\left.23 \mathrm{~cm}^{-1}\right)^{25}$. Calculations of the blueshift of the $2 \mathrm{D}$ band attributed this effect both to stress in the graphene layer ${ }^{26,27}$ or 
scattering from deeper layers in FLG. During the evaporation and cooling down the graphene layer is subjected to tension and compression, inducing small changes in their lattice parameters.

The Raman map in Figure 5, shows a relatively small value of $\mathrm{I}_{\mathrm{G}} / \mathrm{I}_{2 \mathrm{D}}$ ratio $\approx$ $0.2-0.5$. This is an indication of a single layer of graphene ${ }^{3}$. Our experimental

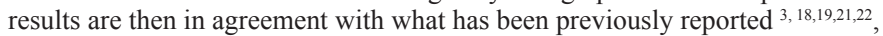
with the advantage that the procedure described here not require a later transfer onto an insulating substrate.
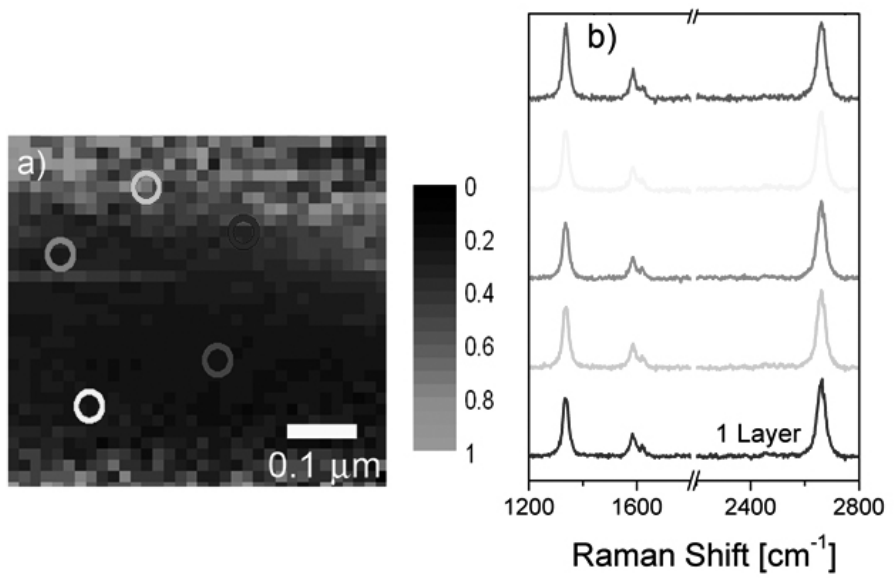

Figure 5. a) Mapping $I_{G} / I_{2 D}$, graphene grown over a metal nanocluster, as detected by optical microscopy, red square in Figure 3. In a), the different circles are selected areas for the corresponding Raman shifts shown in b). Single layer graphene can be clearly recognized in the width and shape of the $2 \mathrm{D}$ peak intensity together with the $\mathrm{I}_{\mathrm{G}} / \mathrm{I}_{2 \mathrm{D}}$ ratios. This result seems inconsistent with the high $\mathrm{D}$ peak intensity shown by the spectra. This high intensity is generally associated to defects. See text for more detail.

The reduction of the $\mathrm{CuO}$ film is induced during the rise in temperature (until $1000^{\circ} \mathrm{C}$ ). Due to the rapid increase in temperature (rate of $90^{\circ} \mathrm{C} /$ $\mathrm{min}$ ), the $\mathrm{CuO}$ film is reduced only on the surface retaining oxygen within the volume. Thus, as graphene growth develops, oxygen can diffuse towards the reduced metal surface and re-oxidize the surface again ${ }^{15}$. This process decreases the catalytic effectiveness of the $\mathrm{Cu}$ surface, which is an advantage in terms of reducing the FLG thickness. The presence of oxygen on the catalyst surface can have an inhibitory role in carbon nucleation and a positive effect for graphene growth.

\section{CONCLUSION}

The growth and deposition of graphene on $\mathrm{SiO}_{2}$ by $\mathrm{CVD}$, has been carried out without any additional chemical or transfer procedure. $\mathrm{A} \mathrm{CuO}$ thin film reduced in $\mathrm{H}_{2}$ ambient was used as a catalyst, while $\mathrm{C}_{2} \mathrm{H}_{2}$ as the carbon source.

During graphene growth, probably oxygen diffuses from the inside of the metallic oxide film toward the surface of the $\mathrm{Cu}$ layer and its catalytic power decreases. This effect allows an increased control over graphene growth. We have found that grain sizes and defects in the graphene sheets obtained by using this method, have similar characteristics to those grown in mono and polycrystalline $\mathrm{Cu}$ (foil or thin films).

\section{ACKNOWLEDGMENT}

This works was partially supported by CONICYT: FONDECYT 11110522, Air Force Office of Scientific Research FA9550-13-1-006 (USA) and ANILLO ACT 1204.

\section{REFERENCES}

[1] K. S. Novoselov, A. K. Geim, S. V. Morozov, D. Jiang, Y. Zhang, S. V. Dubonos, I. V. Grigorieva and A. A. Firsov, Science, 2004, 306, 6666.

[2] C. Soldano, A. Mahmood and E. Dujardin, Carbon, 2010, 48, 2127.

[3] G. Wang, J. Yang, J. Park, X. Gou, B. Wang, H. Liu and J. Yao, J. Phys. Chem. C, 2008, 112, 8192 .

[4] X. Li, W. Cai, J. An, S. Kim, J. Nah, D. Yang, R. Piner, A. Velamakanni,
I. Jung, E. Tutuc, S. K. Colombo, R. S. Ruoff, Science. 324, 1312 (2009).

[5] M. P. Levendorf, C. S. Ruiz-Vargas, S. Garg, J. Park, Nano Lett. 9, 4479 (2009).

[6] Y. Zhang, Z. Li, P. Kim, L. Zhang, C. Zhou, ACS Nano. 6,126(2012).

[7] M. H. Rümmeli, A. Bachmatiuk, A. Scott, F. Börnert, J. H. Warner, V. Hoffman, J-H Lin, G. Cuniberti, B. Büchner, ACS Nano.4, 4206 (2010).

[8] J. Hofrichter, B. N. Szafranek, M. Otto, T. J. Echtermeyer, M. Baus, A. Majerus, V. Geringer, M. Ramsteiner, H. Kurz, Nano Lett. 10, 36 (2010).

[9] J. Chen, Y. Wen, Y. Guo, B. Wu, L. Huang, Y. Xue. D. Geng, D. Wang, G. Yu, Y. Liu, J. Am. Chem. Soc. 133, 17548 (2011).

[10]Y. H. Lee, J. H. Lee, Apply Phys. Lett. 96, 083101 (2010).

[11] A. Ismach, C. Druzgalski, S. Penwell, A. Schwartzberg, M. Zheng, A. Javey, J. Bokor, Y. Zhang, Nature. 10, 1542 (2010).

[12]B.E. Deal and A.S. Grove, J. Appl. Phys. 36, 3770 (1965).

[13] J. Henrie, S. Kellis, S. M. Schultz, and A. Hawkinsl, Optics Express, 12, 9, $1469(2004)$

[14]I. Calizo, A. A. Baladin, W. Bao, F. Miao, C. N. Lau, Nano Lett. 7, 2645 (2007).

[15] S. Poulston, P. M. Parlett, P. Stone, M. Bowker, Surface and Interface Analysis. 24, 811 (1996).

[16]L. M. Malard, M. A. Pimenta, G. Dresselhaus, M. S. Dresselhaus, Phys. Rep. 473, 51 (2009).

[17]K. F. Mak, J. Shan, T. F. Heinz, Phys. Rev. Lett. 104, 176404 (2010).

[18] M. A. Pimenta, G. Dresselhaus, M. S. Dresselhaus, L. G. Cançado, A. Jorio, R. Saito. Phys. Chem. Chem. Phys. 2007; 9: 1276-1290.

[19] L. G. Cançado, M. A. Pimenta, B. R. Nieves, M. S. Dantas, A. Jorio, Phys. Rev. Lett. 93, 247401 (2004).

[20] L. Gao J. R. Guest, N. P. Guisinger, Nano Lett. 10, 3512 (2010).

[21]Y. N. Trehan. Z. Anorg. Allg. Chem. 318, 107 (1962).

[22] A. C. Ferrari, J. C. Meyer, C. Scardaci, C. Casiraghi, M. Lazzeri, F. Mauri, S. Piscanec, D. Jiang, K. S. Novoselov, S. Roth, A. K. Geim, Phys. Rev. Lett. 97, 187401 (2006).

[23] S. Berciaud, S. Ryu, L. E. Brus, T. F. Heinz. Nano Lett. 9, 346 (2009).

[24]D. Yoon, H. Moon, Y-W. Son, J. S. Choi, B. H. Park, Y. H. Cha, Y. D. Kim, H. Cheong, Phys. Rev. B, 80, 125422 (2009).

[25] A. Das, B. Chakraborty, A. K. Sood, Bull. Mater. Sci. 31, 579 (2008).

[26] R. Narula, N. Bonini, N. Marzari, S. Reich, Phys. Rev. B. 85, 115451 (2012).

[27]E. Del Corro, M. Taravillo, V. G. Baonza, Physical Review B. 85, 033407 (2012). 